\title{
Direct and correlated responses to selection for 4-week body weight in two lines of Japanese quails
}

\begin{abstract}
Summary
Data on 29,411 quails of two selected lines alongwith a control line were examined over nine generations. Significant genetic gains/generation for 4-week body weight were realized in the two strains $(3.70$ and $3.10 \mathrm{~g})$. Significant correlated genetic changes were also observed in early body weights (day-old to 3-weeks) as well as in 16-week body weight. Egg number and sexual maturity did not show any significant response while egg weight and egg mass showed desirable genetic gains. Natural selection did not seem to exert any effect. Inbreeding levels of 0.32 to $0.43 \%$ per generation did not appear to be of any significance in affecting the response. Realized heritabilities $(0.21-0.24)$ were reasonably consistent between sexes and matched fairly well with the nine-generation pooled sire-component heritabilities of $0.20 \pm 0.04$ and $0.25 \pm 0.04$ in the two lines. There was evidence of maternal effects as indicated by excess of dam-over the sire-component heritability. Time-trend in heritabilities was non-significant. There was good agreement between the predicted and realized genetic gains.
\end{abstract}

Key Words: selection, genetic gain, inbreeding, realized heritability, quails

\section{Zusammenfassung}

Titel der Arbeit: Direkte und korrelierte Selektionserfolge einer Selektion nach dem 4-Wochen Körpergewicht in zwei Wachtellinien

In einem Selektionsexperiment konnten die Daten von 29411 Wachteln von zwei Selektions- und einer Kontrollinie dber neun Generationen ausgewertet werden. Flir das Selektionsmerkmal „4-WochenKörpergewicht" wurde in beiden Selektionslinien ein bedeutender genetischer Fortschritt je Generation erreicht. Bei der Mehrzahl der weiteren erfaßten Leistungsmerkmale wie z, B, der Körpergewichte zu unterschiedlichem Alter bis zur 16. Woche oder dem Eigewicht konnten signifikante korrelierte Selektionserfolge nachgewiesen werden, wathrend diese fur Merkmale wie die Eizahl oder Legereife nicht erreicht wurden. Zwischen den Selektionslinien ergaben sich keine nennenswerten Unterschiede und der Inzuchtzuwachs von $0,32 \%$ je Generation auf 2,88 \% nach 9 Generationen hat keinen Einfluß auf das Leistungsverhalten genommen. Die Heritabilitat des Selektionsmerkmals wurde geschatzt und diskutiert, wobei kein Zeittrend erkennbar war und sich eine gute Ubereinstimmung zwischen dem vorhergesagten und dem realisierten Schatzwert, der bei den Selektionslinien bei 0,23 bzw. 0,21 lag, ergab

Schlusselworter: Selektion, genetischer Gewinn, Inzucht, realisierte Heritabilitat, Wachtel

\section{Introduction}

Selection experiments in animals not only provide useful information about the efficacy of a particular selection procedure in improving the performance of a population under selection but also provide empirical test of selection theory and/or of statistical estimates of genetic parameters (HILL, 1972). Japanese quail (Coturnix coturnix japonica) has been employed as a pilot animal in quantitative genetic studies because of its short generation interval and lesser resource requirement (ANTHONY et al., 1996). Selection experiments with quails have examined the role of selection environment on short- and long-term selection responses (MARKS, 1996). MACHA 
and BECKER (1976) and NESTOR et al., (1982) also reported short-term responses to selection for body weight. However, information on responses in correlated traits like egg production, egg weight etc is meagre (NESTOR and BACON, 1982; DARDEN and MARKS, 1988; ANTHONY et al., 1996). The present paper study was conducted with the objective of evaluating the population structure, inbreeding levels, selection differentials, the direct response to selection for 4-week body weight, and the correlated responses occurring in body weights at other ages and in egg production traits. The paper also deals with the evaluation of time trends in heritabilities over generations, and estimating realized heritabilities which permit the effectiveness of selection.

\section{Materials and Methods}

Populations: Two lines of Japanese quails (PQ1 and PQ2) undergoing selection for 4week body weight and a pedigreed control line (PQ3) maintained at the University farm provided the experimental material. The control line, which represented a genetic background similar to the selected strains, was used to measure the environmental trend over generations. To minimize genetic drift in the control line as far as possible, each sire contributed a sire and each dam contributed a dam as breeders in succeeding generations. Mass selection for 4-week body weight was practiced in the two selected lines. The control line was reproduced without any intentional selection. A total of 29411 quails of three lines consisting of 10,329 of PQ1, 11871 of PQ2 and 7211 of $\mathrm{PQ} 3$, respectively were reared over nine generations. The average numbers of quails tested at 4 weeks, the effective number of sires and dams, and the effective population size during the course of present study are given in Table 1.

Table I

Population structure and inbreeding averaged over generations

\begin{tabular}{lccccccc}
\hline Line & $\mathrm{Nm}$ & $\mathrm{Nf}$ & $\mathrm{Ne}$ & \multicolumn{3}{c}{ No. of quails } & \multirow{2}{*}{$\Delta \mathrm{F}(\%)$} \\
& & & & $\mathrm{M}$ & $\mathrm{F}$ & $\mathrm{M}+\mathrm{F}$ & \\
\hline PQ1 & 55.5 & 140.3 & 158.3 & 576 & 570 & 1146 & 0.32 \\
PQ2 & 54.9 & 146.1 & 158.8 & 664 & 655 & 1319 & 0.32 \\
$\begin{array}{l}\text { (PQ3) } \\
\text { (Control) }\end{array}$ & 40.2 & 98.6 & 116.9 & 403 & 398 & 801 & 0.43 \\
\hline
\end{tabular}

$N_{m} . N_{6} N_{2}$ refer to effective no. of sires, dams and population size; $\Delta F(\%)=$ inbreding /generation; $M$ and $F$ refer to maies and females

Full-and half-sib mating were avoided in all the lines so as to keep inbreeding at a low level. The mating were accomplished in cages by rotating the male to its allotted dams on a daily basis. The chicks were brooded in floor pens during first generation. In the subsequent generations, however, the chicks were brooded and reared in quail battery brooders. The selected populations and the control line were grown inter-mingled in order that temperature, humidity, light intensity and other variables nould be as similar as possible among populations. Two generations were obtained per year.

Traits: Four-week body weight (BW4) was recorded on all the quails of both the sexes. Body weights were also recorded at day-old (BW 0); 1 week (BW 1), 2 week 
(BW2) and 3 week (BW3) of unsexed quails. The traits recorded on adult female quails were: age at $50 \%$ production (ASM); egg number to 16 weeks of age (EN16); body weight at 16 weeks of age (BW16) and egg weight recorded as average of all the eggs laid in the I6th week (EW16). Relative growth rate from 4 to 16 weeks of age (RGR) was computed as RGR= (BW 16- BW 4)* 100/BW4. Other derived traits included egg weight as \% of 16-week body weight (EW\% BW 16); egg mass to 16 weeks of age (EM 16) obtained as multiple of egg number and egg weight, and egg production efficiency i.e. egg mass divided by 16-week body weight (EPE).

Statistical Analysis: Hatch adjusted Least-square means (HARVEY, 1988) were used for the estimation of phenotypic and genetic changes. The realized genetic gain per generation was estimated as deviation of the selected line means from the control line means regressed over generations. The effective number of sires and dams were used for the computation of effective population size and inbreeding as per GOWE et al. (1959). The effective selection differential was calculated by weighing each parent by the number of offspring available at 16 weeks of age. The standardized selection differential for the selected trait was obtained by dividing the effective selection differential with the phenotypic standard deviation. Realized heritability was obtained as (i) simple regression of response on cumulative selection differential ( $\left.b_{R s}\right)$ and (ii) the ratio of cumulative response (CR) to cumulative selection differential (CS) for the selected trait (HILL, 1972). The heritabilities were also calculated from full-sib analysis as per the procedure outlined by BECKER (1984).

\section{Results and Discussion}

Control Population: The estimates of environmental changes in the control line (PQ 3) for different traits are presented in Table 3. Regression of means on generation numbers were positive from day-old to 4 week body weights but were statistically significant for 4-week body weight only. Significant systematic changes in performance of the control line had been reported in some of the earlier selection experiments (NESTOR et al., 1982). The performance of the control for 4-week body weight showed fluctuations over generations (Table 2). Environmental variations as influenced by season of hatching could account for this variation among generations since quails were hatched twice a year in different seasons. However, the pattern of changes in means of control over generations fairly matched with those observed for the two selected lines (Table 2) indicating possibly these to be of the environmental origin. The selection differentials computed due to random selection of control line breeders were essentially zero thus further strengthening the lack of a genetic trend in the control line. Rate of inbreeding per generation was low $(0.43 \%)$ and accrued to be $3.87 \%$ over nine generations and is therefore unlikely to have affected the performance and variance to any significant degree. The estimates of heritability for the selected trait in the control did not change over generations (Table 5). Keeping in view the size of the breeding population maintained and the mating procedure adopted to minimize genetic drift and inbreeding, coupled with the lack of changes in heritabilities, there appeared no evidence of a genetic change in the control population.

Mean Performance and Genetic Gains: The means of the selected limes expressed as 
deviations from the control means for the selected and correlated traits are presented in Fig. 1 and 2 while the estimates of genetic gains for all the traits are given in Table 3 . The means for sex-pooled 4-week body weight for the three lines are given in Table 2.

Table 2

Means and standard deviations (SD) for sex pooled 4-week body weight $(\mathrm{g})$

\begin{tabular}{|c|c|c|c|c|c|c|c|c|c|}
\hline \multirow[t]{2}{*}{ Line } & \multicolumn{9}{|c|}{ Generation } \\
\hline & 1 & 2 & 3 & 4 & 5 & 6 & 7 & 8 & 9 \\
\hline PQ1 & $\begin{array}{r}89.7 \\
\pm 16.8\end{array}$ & $\begin{array}{l}122.2 \\
\pm 11.7\end{array}$ & $\begin{array}{l}131.3 \\
\pm 15.4\end{array}$ & $\begin{array}{r}95.0 \\
\pm 20.1\end{array}$ & $\begin{array}{l}122.1 \\
\pm 16.7\end{array}$ & $\begin{array}{l}128.4 \\
\pm 17.7\end{array}$ & $\begin{array}{r}158.0 \\
\pm 14.6\end{array}$ & $\begin{array}{r}149.0 \\
\pm 20.1\end{array}$ & $\begin{array}{r}164.7 \\
\pm 16.0\end{array}$ \\
\hline PQ2 & $\begin{array}{r}85.4 \\
\pm 16.2\end{array}$ & $\begin{array}{l}117.0 \\
\pm 10.3\end{array}$ & $\begin{array}{l}127.3 \\
\pm 11.7\end{array}$ & $\begin{array}{r}90.4 \\
\pm 18.5\end{array}$ & $\begin{array}{r}118.7 \\
\pm 16.5\end{array}$ & $\begin{array}{l}123.3 \\
\pm 15.4\end{array}$ & $\begin{array}{l}147.0 \\
\pm 14.3\end{array}$ & $\begin{array}{l}140.4 \\
\pm 19.1\end{array}$ & $\begin{array}{r}155.6 \\
\pm 14.8\end{array}$ \\
\hline PQ3 & $\begin{array}{r}79.3 \\
+14.6 \\
\end{array}$ & $\begin{array}{l}104.9 \\
\pm 9.4\end{array}$ & $\begin{array}{r}103.5 \\
\pm 10.9\end{array}$ & $\begin{array}{r}77.4 \\
\pm 13.0 \\
\end{array}$ & $\begin{array}{l}101.3 \\
\pm 16.8\end{array}$ & $\begin{array}{l}103.1 \\
\pm 13.9 \\
\end{array}$ & $\begin{array}{r}118.8 \\
\pm 13.7 \\
\end{array}$ & $\begin{array}{r}103.3 \\
\pm 18.1 \\
\end{array}$ & $\begin{array}{r}115.8 \\
\pm 14.1\end{array}$ \\
\hline
\end{tabular}

Selected traits: Quails of PQ1 were significantly heavier than those of PQ2 (Table 2). Both the selected strains showed a marked increase in 4-week body weight indicating significant genetic improvement (Fig.1 and Table 3). The estimates of response were of similar magnitude in both the sexes and in both the strains $(3.10 \pm 0.74$ to $3.80 \pm 0.89$ g). The magnitude of genetic gain observed in the present study matched fairly well with those of NESTOR et al. (1982); DARDEN and MARKS (1988) and MARKS (1990) who reported genetic gains of 3 to $4 \mathrm{~g}$ per generation during the first 10 generations of selection. The selected strains PQ1 and PQ2 had 19.7 and $12.5 \%$ higher body weights (sex-pooled) than the control line in $\mathrm{S}_{1}$ generation. By $\mathrm{S}_{9}$, the superiority of the selected strains over the control line had increased to 44.2 and 35.9 $\%$. MARKS and LEPORE (1968) also reported percentage deviations from control in the range of 30 to $50 \%$ during the first $6-10$ generations of selection. Females were significantly heavier than males in all the lines. Sexual dimorphism for body weight (measured as ratio of male to female body weight) did not show any significant genetic change over generations $(b=-0.06 \pm 0.24$ and $-0.03 \pm 0.23)$ in PQ1 and PQ2.

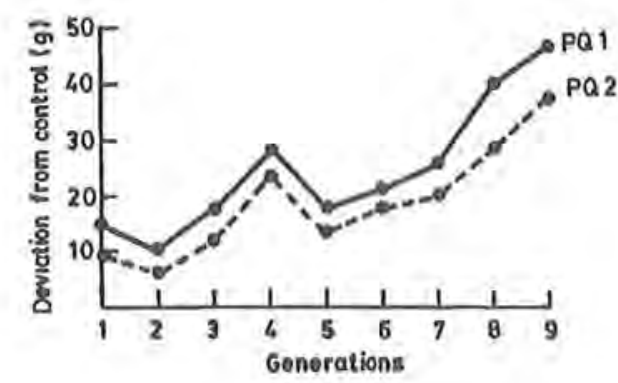

Fig. 1: Direct response in 4-week body weight

Correlated trait: Quails of PQ1 were, in general, heavier than those of PQ2 for body weights from day-old to three weeks of age (Fig. 2). The estimates of correlated 


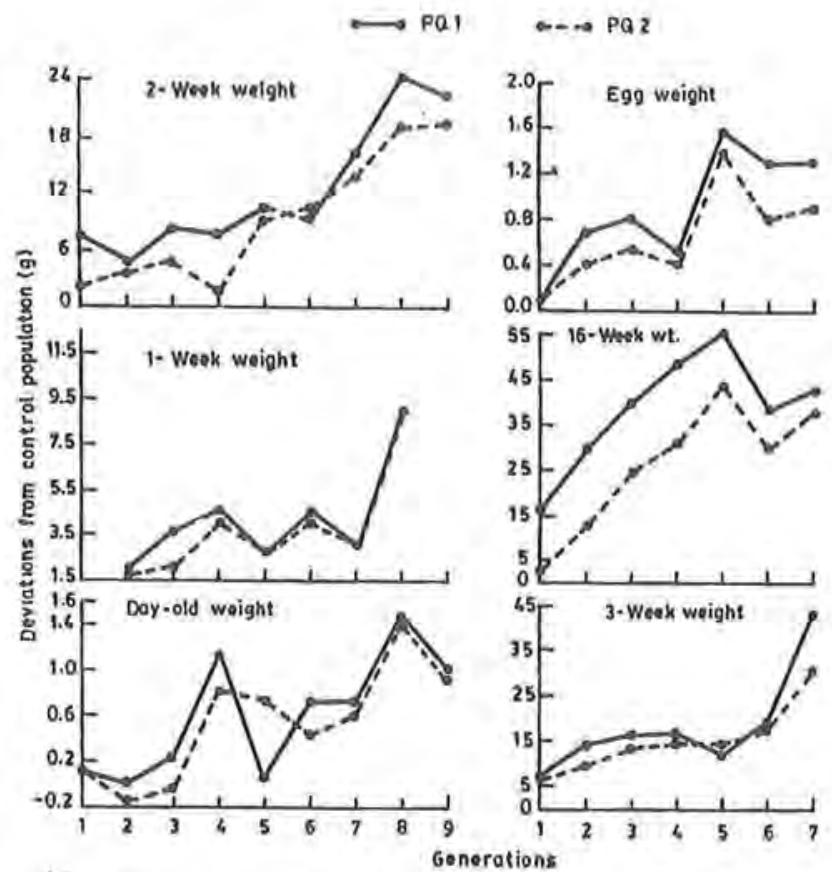

Fig. 2: Correlated responses in early body weights, adult body weight and egg weight

genetic changes for day-old, 1-week, 2-week and 3-week body weights were significant (Table 3). The magnitude of the genetic change did not differ significantly between the strains. DARDEN and MARKS (1988) also observed significant correlated response in 2 -week body weight $(b=1.07 \pm 0.32$ to $1.58 \pm 0.33 \mathrm{~g})$ as a consequence of selection for 4 -week body weight. The significant positive genetic changes in early body weights implied the existence of a high genetic correlation of 4week body weight with early body weights. Genetic correlation's ranging from 0.7 to 1.0 between early and 4-week body weight were recorded in the base populations of these lines (BRAH et al., 1997).

The 16-week body weight of female quails in $\mathrm{S}_{1}$ generation of PQ1, PQ2 and control line were 174,161 and $158 \mathrm{~g}$ respectively. These increased to 228,223 and $185 \mathrm{~g}$ respectively by 9th generation. The selected strains PQ1 and PQ2 exhibited 23.2 and $20.5 \%$ superiority over the control line in 9 th generation. Both the strains registered significant genetic changes to the tune of 4 to $5.7 \mathrm{~g}$ (Table 3). These values match closely with those reported by DARDEN and MARKS (1988) for BW16 during the first 10-11 generations of selection. The relative growth rate from 4 to 16 weeks did not change significantly in PQ1 but showed a significant improvement in PQ2. DARDEN and MARKS (1988) observed significant differences in relative growth rate from 4 to 16 weeks between high- and low- body weight selected lines.

Age at $50 \%$ egg production and egg number to 16 weeks of age did not show significant genetic change. This observation is in agreement with those of MARKS (1979). However, DARDEN and MARKS (1988) recorded a decrease in egg production due to selection for 4-week body weight over 10 generations. Egg weight 
in the present study exhibited a significant genetic improvement of similar magnitude in both the selected lines. This may have resulted from the increase in 16-week body weight. Egg weight expressed as a $\%$ of 16 -week body weight (EW\% BW) did not change over generations which implied that the increase in egg weight was in direct proportion to the corresponding improvement in adult body weight. Egg mass output showed significant genetic improvement in both the lines. The direct measurement of efficiency of feed conversion for eggs is cumbersome and expensive. NORDSKOG et al. (1974) have shown that egg production efficiency (EPE) i.e. egg mass/body weight can be used as an indirect measure of feed efficiency for egg production. The EPE did not show significant genetic improvement in any of the lines.

Table 3

Regression of response on generation numbers $(b \pm S E)$

\begin{tabular}{|c|c|c|c|c|c|}
\hline \multirow[t]{2}{*}{ Traits } & \multicolumn{3}{|c|}{ Phenotypic response } & \multicolumn{2}{|c|}{ Genetic response } \\
\hline & PQ3 & PQI & $\mathrm{PQ} 2$ & PQ1 & $\mathrm{PQ} 2$ \\
\hline \multicolumn{6}{|l|}{ Selected } \\
\hline BW4 -Male(g) & $3.40 \pm 1.46^{*}$ & $7.00 \pm 1.90^{* *}$ & $6.50 \pm 1.70^{* *}$ & $3.60 \pm 0.74^{\star * x}$ & $3,10 \pm 0.52^{*+}$ \\
\hline BW4-Female(g) & $3.50 \pm 1.63 *$ & $7.30 \pm 2.10^{* *}$ & $6.60 \pm 1.97^{* *}$ & $3.80 \pm 0,89^{* k}$ & $3.10 \pm 0.74 \%$ \\
\hline $\mathrm{M}+\mathrm{F}$ & $3.50 \pm 1.51^{*}$ & $6.90 \pm 2.02^{\bullet *}$ & $6.50 \pm 1.87^{k *}$ & $3,70 \pm 0.90^{* *}$ & $3.10 \pm 0.69^{* *}$ \\
\hline \multicolumn{6}{|l|}{ Correlated: } \\
\hline BWO(g) & $0,09 \pm 0,07$ & $0.25 \pm 0.10^{20}$ & $0.25 \pm 0.10^{* *}$ & $0.15 \pm 0.04^{* *}$ & $0.16 \pm 0.04^{* *}$ \\
\hline $\mathrm{BW} 1(\mathrm{~g})$ & $1.00 \pm 0.95$ & $1.72 \pm 1.27$ & $1.86 \pm 1.22$ & $0.72 \pm 0.36^{+}$ & $0.86 \pm 0.34^{\circ 4}$ \\
\hline BW2(g) & $2.30 \pm 1.60$ & $4.60 \pm 1.38^{\circ e}$ & $4,70 \pm 1.33^{* *}$ & $2.30 \pm 0.46^{\text {vv }}$ & $2.40 \pm 0.32 * 4$ \\
\hline BW3(g) & $2.10 \pm 1.85$ & $6.10 \pm 3.00^{*}$ & $5.30 \pm 2.32^{4}$ & $4.00 \pm 1.55^{* *}$ & $3.20 \pm 0.80^{* \bullet}$ \\
\hline BW16(g) & $3.82 \pm 0.90^{\circ 0}$ & $7.82 \pm 1.71 * *$ & $9.54 \pm 1.89^{\circ 2}$ & $4.00 \pm 1.92^{* k}$ & $5.70 \pm 1.51^{* * *}$ \\
\hline RGR (\%) & $-2,19 \pm 1,89$ & $-1.05 \pm 2.24$ & $0.59 \pm 2.34$ & $1.14 \pm 0.82$ & $2.78 \pm 0.88^{4 *}$ \\
\hline $\operatorname{ASM}(d)$ & $-0.56 \pm 0,65$ & $-0.56 \pm 0.71$ & $-0.67 \pm 0.64$ & $-0.10 \pm 0,33$ & $-0.11 \pm 0.21$ \\
\hline ENI6 & $1.23 \pm 0.70$ & $1.05 \pm 0.81$ & $1.81 \pm 0.80^{\circ}$ & $0.18 \pm 0.49$ & $0.32 \pm 0.43$ \\
\hline EW $16(\mathrm{~g})$ & $0.24 \pm 0.08^{k *}$ & $0.44 \pm 0.10^{* 4}$ & $0.39 \pm 0.09^{* *}$ & $0.20 \pm 0.06^{\mathrm{ve}}$ & $0.15 \pm 0.06^{* *}$ \\
\hline EW\%/BW16 & $-0.01 \pm 0.02$ & $-0.01 \pm 0.03$ & $-0.09 \pm 0.03^{* \alpha}$ & $-0.01 \pm 0.01$ & $-0.10 \pm 0.02^{*}$ \\
\hline EM (g) & $23.42 \pm 9.50^{* *}$ & $30.71 \pm 11.8^{* 00}$ & $38.64 \pm 11.8^{* 4}$ & $7.29 \pm 2.73 * *$ & $15.21 \pm 3.42^{\neq *}$ \\
\hline EPE & $0.08 \pm 0.05$ & $0.06 \pm 0.05$ & $0.07 \pm 0.05$ & $-0.02 \pm 0.01$ & $0.01 \pm 0.01$ \\
\hline
\end{tabular}

$* \mathrm{P} \leq 0.10 ; * \mathrm{p} \leq 0.05$

Selection Differentials: The expected and effective selection differentials for males and females and averaged over the two sexes are given in Table 4. Selection differentials were higher in males than in females. The values of selection intensity 
corresponded to the selection of best 20 to $25 \%$ males and best 50 to $55 \%$ females. Regression of selection differential and selection intensity on generation number (Table 4), with the exception of males in both the strains, were non-significant implying that selection pressure remained uniform across generations. The significantly positive regression coefficients for males primarily resulted from the low values recorded in the $S_{1}$ generation which was due to the use of more number of sires from relatively lesser number of available individuals. The ratio of effective to expected selection differentials was close to unity indicating that natural selection and /or chance did not influence selection for 4-week body weight.

Table 4

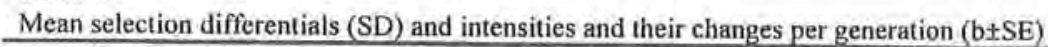

\begin{tabular}{|c|c|c|c|c|c|c|}
\hline \multirow[t]{2}{*}{ Statistic } & \multirow[t]{2}{*}{ Line } & \multirow[t]{2}{*}{ Sex } & \multicolumn{2}{|c|}{ Selection differential $(\mathrm{g})$} & \multirow[t]{2}{*}{ Ratio } & \multirow[t]{2}{*}{ Intensity } \\
\hline & & & Exp. & Eff. & & \\
\hline \multirow[t]{6}{*}{ SD } & PQI & M & 20.1 & 20.0 & 1.00 & 1.31 \\
\hline & & F & 14.9 & 14.3 & 0.96 & 0.88 \\
\hline & & AV. & 17.4 & 17.2 & 0.98 & 1.09 \\
\hline & $\mathrm{PQ} 2$ & M & 19.8 & 19.8 & 1.00 & 1.43 \\
\hline & & F & 11.8 & 11.7 & 0.99 & 0.82 \\
\hline & & Av. & 15.9 & 15.7 & 0.99 & 1.13 \\
\hline \multirow[t]{6}{*}{$\mathrm{b} \pm \mathrm{SE}$} & PQ1 & M & $1.46 \pm 0.66^{*}$ & $1.61 \pm 0.66^{*}$ & - & $0.10 \pm 0.06$ \\
\hline & & F & $0.31 \pm 0.46$ & $0.26 \pm 0.41$ & - & $0.01 \pm 0.03$ \\
\hline & & Av. & $0.88 \pm 0.54$ & $0.94 \pm 0.51$ & - & $0.06 \pm 0.05$ \\
\hline & PQ2 & M & $1.04 \pm 0.28^{* 6}$ & $0.99 \pm 0.26^{\text {* }}$ & - & $0.05 \pm 0.04$ \\
\hline & & F & $0.46 \pm 0.46$ & $0.31 \pm 0.39$ & - & $0.01 \pm 0.03$ \\
\hline & & Av. & $0.75 \pm 0.33$ & $0.65 \pm 0.32$ & - & $0.03 \pm 0.04$ \\
\hline
\end{tabular}

Ratio $=$ effective/ expected selection differential;

$p \leq 0.10$; $p \leq 0.05$

Inbreeding: Inbreeding averaged to be $0.32 \%$ per generation for the selected strains and accrued to be $2.88 \%$ over nine generations. These levels of inbreeding particularly with the avoidance of mating of relatives are unlikely to have influenced the performance of the selected lines. The drift and sampling error variance per generation, computed as per HILL (1980), were low, suggesting that these factors were well controlled.

Heritability: Heritabilities of 4-week body weight pooled on three-generation as well as on nine-generation basis, along with the regression of heritabilities on generations ( $\mathrm{b} \pm \mathrm{SE}$ ), are presented in Table 5 . The dam-component estimates were two to three times higher than the corresponding sire-component estimates over lines indicating the existence of maternal and/or non-additive genetic effects (BECKER, 1984). The standard errors associated with estimates from different components were low enough to make the estimates significantly different from zero. Scanty and highly variable estimates have been reported in the literature from different components for early body weight (MARKS and LEPORE, 1968; SEFTON and SIEGEL, 1974 and MARKS, 1990). The literature estimates did not show any clear differences between the sire and dam components. MARKS (1990) on the basis of the estimates reported in the literature for juvenile body weights found the estimates from different methods to vary between 0.17 and 0.70 with a mean of 0.40 for the 30 estimates. The nine-generation 
pooled estimates from the sire plus dam components in the present study agree fairly well with the literature estimates.

The individual-generation estimates fluctuated considerably over generations but did not show any consistent time-trend. The regression of heritabilities on generation numbers were non-significant. It implied the existence of significant genetic variability in the populations to warrant continued response to selection.

Table 5

Heritability of 4-wk body weight and linear regression (b $\pm S E$ ) of heritability on generations

\begin{tabular}{llccc}
\hline Line & Gen, & Sire Comp. & Dam Comp. & Sire+Dam Comp. \\
\hline PQ1 & $1-3$ & $0.182 \times 0.057$ & $0.441 \pm 0.072$ & $0.309 \pm 0.035$ \\
& $4-6$ & $0.235 \pm 0.066$ & $0.373 \pm 0.073$ & $0.306 \pm 0.037$ \\
& $7-9$ & $0.179 \pm 0.080$ & $0.510 \pm 0.097$ & $0.347 \pm 0.043$ \\
PQ2 & $1-3$ & $0.311 \pm 0.078$ & $0.522 \pm 0.074$ & $0.473 \pm 0.041$ \\
& $4-6$ & $0.233 \pm 0.075$ & $0.408 \pm 0.073$ & $0.358 \pm 0.040$ \\
& $7-9$ & $0.210 \pm 0.078$ & $0.661 \pm 0.090$ & $0.441 \pm 0.044$ \\
PQ3 & $1-3$ & & & \\
& $4-6$ & $0.030 \pm 0.082$ & $0.810 \pm 0.122$ & $0.430 \pm 0.045$ \\
PQ1 & $7-9$ & $0.310 \pm 0.103$ & $0.430 \pm 0.092$ & $0.390 \pm 0.066$ \\
PQ2 & $1-9$ & $0.480 \pm 0.151$ & $0.770 \pm 0.134$ & $0.640 \pm 0.082$ \\
PQ3 & $1-9$ & $0.236 \pm 0.037$ & $0.465 \pm 0.061$ & $0.350 \pm 0.037$ \\
b \pm SE & $1-9$ & $0.256 \pm 0.033$ & $0.652 \pm 0.097$ & $0.454 \pm 0.046$ \\
PQ1 & & $0.381 \pm 0.116$ & $0.746 \pm 0.008$ & $0.562 \pm 0.057$ \\
PQ2 & & & & \\
PQ3 & & $-0.017 \pm 0.015$ & $0.254 \pm 0.251$ & $-0.004 \pm 0.016$ \\
\hline
\end{tabular}

Table 6

Realized heritabilities for 4-week body weight

\begin{tabular}{|c|c|c|c|c|c|c|}
\hline \multirow[t]{3}{*}{ Line } & \multicolumn{5}{|c|}{ Method } & \\
\hline & \multicolumn{3}{|c|}{$\mathrm{CR} / \mathrm{CS}$} & \multicolumn{3}{|c|}{$\mathrm{b}_{\mathrm{RS}}$} \\
\hline & M & $\mathrm{F}$ & Av. & M & $\mathrm{F}$ & AV. \\
\hline PQ1 & 0,206 & 0.230 & 0.218 & $0.217 \pm 0.044$ & $0.236 \pm 0.055$ & $0.23 \mathrm{I} \pm 0.052$ \\
\hline $\mathrm{PO} 2$ & 0.213 & 0.217 & 0.216 & $0.211 \pm 0.039$ & $0.215 \pm 0.053$ & $0.211 \pm 0.039$ \\
\hline
\end{tabular}

CR/CS $=$ Cumulative response/cumulative selection differential

$b_{\text {HS }}=$ Regression of cumulative response on cumulative selection differential

Realized Heritabilities vis a vis Effectiveness of Selection: The realized heritabilities estimated by both the methods (Table 6) were fairly consistent between sexes and populations $(0.206$ to 0.236$)$. The sizes of the standard errors in all the cases were low. The realized heritabilities provide the most useful empirical description of the effectiveness of selection (FALCONER, 1989). The values of realized heritabilities averaged over methods and sexes for the two strains worked out to be 0.23 and 0.21 . These values were in agreement with the sire-component heritability of the two strains (0.24 and 0.26 ) implying a high degree of correspondence between the realized and expected genetic gains. The results of several earlier selection experiments with poultry and other laboratory animals indicated that the realized selection responses match fairly well with the predicted responses for short-term experiments. 
The results of the study demonstrated the genetic stability of the control population vis $a$ vis separation of genetic and environmental trends. Selection for 4 -week body weight was effective in its genetic improvement with a high degree of correspondence between the expected and realized genetic changes. Significant desirable correlated responses were evident for juvenile body weight, adult weight and egg weight. Natural selection did not appear to counter act artificial selection. Lack of changes in heritabilities over generations implied the existence of significant genetic variability in the populations to warrant continued response to selection for 4-week body weight.

\section{References}

ANTHONY, N.B.; NESTOR, K.E.; MARKS, H.L: Short-term selection for four-week body weight in Japanese quail. Poult. Sci. 75 (1996), 1192-1197 BECKER, W.A.: Manual of Quantitativc Genetics (4 $4^{\text {th }}$ Ed.) Academic Enterprises, Pullman. WA, USA, (1984)

BRAH, G.S.; CHAUDHARY, M.L.; SANDHU, J.S.: Genetic analysis of body weight in three lines of Japanese quails. Ind. J. Poult. Sci. 32 (1997), 242-248

DARDEN, J.R.; MARKS, H.L.; Divergent selection for growth in Japanese quail under split and complctc nutritional environments. I Genetic and correlated responses to selection. Poult. Sci. 67 (1988), 519-529

FALCONER, D.S.: Introduction to Quantitative Genetics. English Language Book Society, Longman, (1989)

GOWE, R.S.; JOINNSON, A.S.; DOWNS, J.H.; GIBSON, R.; MOUNTAIN, W.F.; STRAIN J.H.; TINNEY, B.F.; Environment and poultry breeding problems. 4. The value of a random bred control strain in a selection study, Poult. Sci. 38 (1959), 443-462

HARVEY, W.R: Least-Squares Analysis of Data with Unequal Subclass Numbers. United States Department of Agriculture, Agricultural Research Science and Education Administration, (1988) HILL, W.G.:
Estimation of genetic change. 1. General theory and design of control populations. Anim. Breed. Abstr, HILL, W.G.: $40(1972), 1-5$

Design of quantitative genetic selection experiments. In: ROBERTSON, A. (Ed). „Selection Experiments in Laboratory and Domestic Animals". Farnham Royal, Slough,UK, Commonwealth Agricultural Bureaux (1980), 1-13

MACHA, A.M.; BECKER, W.A. :

Comparison of predicted with actual body weight selection gains of Coturnix coturnix japonica.

MARKS, H.L.: Theor. Appl. Genet. 47 (1976), 251-255

Changes in unselected traits accompanying long-term selection for 4-week body weight in Japanese MARKS, H.L.: quail. Poult. Sci. 58 (1979), 269-274

MARKS, H.L.: Genetics of growth and meat production in other galliforms. In: CRAWFORD, R.D. (Ed)" Poulity Genetics and Breeding", pp 677-90, Elsevier, Amsterdam, (1990)

Long.term selection for body weight in Japanese quail under different environments. Poult. Sci. 75 (1996), 1198-1203

MARKS, H.L.; LEPORE, P.D.:

Growth rate inheritance in Japanese quail. 2. Early responses to selection under different nutritional environments. Poult. Sci. 68 (1968), 455-459

NESTOR, K.E.; BACON, W.L.:

Divergent selection for body weight and yolk precursor in Coturnix cotirnix japonica. 3. Correlated responses in mortality, reproduction traits and adult body weights. Poult. Sci. 61 (1982), 2137-2142

NESTOR, K.E.; BACON, W.L.; LAMBIO, A.L.:

Divergent selection for body weight and yolk precursor in Coturnix coturnix japonica. 1. Selection response, Poult. Sci. 61 (1982), 12-17 
NORDSKOG, A.W.; TOLMAN, H.S.; CASEY, D.W.; LIN, C.Y.;

Selection in small populations of chickens. Poult. Sci. 53 (1974), 1188-1219

SEFTON, A.E.; SIEGEL, P.B.:

Inheritance of body weight in Japanese quails. Poult. Sci. 53 (1974), 1597-1603

Received: $1999-10-08$

Accepted: 2000-10-11

Authors' address

GURVINDER S. BRAH,B.Sc.,M.Sc.,PhD

MOTI L. CHAUDHARY, B.Sc.,M.Sc.,PhD

JAGTAR S. SANDHU, B.V.Sc.,M.Sc.,PhD

Deptt. of Animal Breeding \& Genetics

PAU,Ludhiana-141004, India 